\title{
Is Cholecystectomy a cause of difficult biliary cannulation in endoscopic retrograde cholangiopancreatography?
}

\author{
R.E. Cankurtaran', R. Atalay ${ }^{2}$, Y.H. Polat', F. Kivrakoglu', M. Tahtac1' ${ }^{1}$, O. Ersoy ${ }^{1}$ \\ (1) Ankara Yildirim Beyazit University Faculty of Medicine Department of Gastroenterology, Ankara, Turkey; (2) Ankara City Hospital Department of Gastroenterology, \\ Ankara, Turkey.
}

\begin{abstract}
Background and study aim: In European Society of Gastrointestinal Endoscopy guidelines, biliary cannulation of naive papillae is defined as difficult in the presence of more than 5 papilla contacts, more than 5 min cannulation time or more than one unintended pancreatic duct cannulation or opacification. It is not known whether cholecystectomy is a cause of difficult biliary cannulation. This study aimed to investigate whether cholecystectomy (CCY) is a cause of difficult biliary cannulation in patients who have undergone Endoscopic Retrograde Cholangiopancreatography (ERCP) for choledocholithiasis.

Patients and methods: Adult patients with naive papillae and those who underwent ERCP for common bile duct stones and/or sludge were included in this retrospective study. Patient demographics, clinical presentation (acute cholangitis, biliary pancreatitis or biliary colic), periprocedural data including laboratory and radiological findings and ERCP results were compared between no-CCY and post-CCY groups.

Results: 438 patients were included in the present study and 347 of these patients were in the no-CCY group and 91 patients were in post-CCY group. A statistically significant difference was found in the number of patients with difficult cannulation in the post-CCY group $(n=30,33.0 \%)$ patients compared to the noCCY group $(n=67,19.3 \%)(p=0.011)$. According the multivariate analyses results, presence of history of cholecystectomy was found an independent risk factor of difficult cannulation (Odds ratio: 2.014; $95 \%$ Cl 1.205-3.366; $p=0.008$ ).

Conclusions: The results showed that biliary cannulation was significantly more difficult in patients with cholecystectomy who underwent ERCP for common bile duct stones. (Acta gastroenterol. belg., 2021, 84, 563-569).
\end{abstract}

Keywords: cholecystectomy; difficult cannulation; ERCP.

\section{Introduction}

Endoscopic retrograde cholangiopancreatography (ERCP) is a technically challenging procedure that has been used in the diagnosis and treatment of many pancreatobiliary diseases for nearly 50 years. Despite advances in endoscopic device, accessory, and imaging technologies in the last decade, selective biliary cannulation (SBC), which is accepted as a precondition for a successful ERCP, has a failure rate of 15-35\% (1-3).

Difficult biliary cannulation has been described differently in previous studies. According to the guidelines published by the European Gastrointestinal Endoscopy Association (ESGE) in recent years, difficult cannulation is defined as the presence of any of the following three conditions (4,5): (1) more than 5 papilla contacts while trying to achieve cannulation, (2) more than 5 minutes cannulation time after touching the papilla, and (3) more than one unintended pancreatic duct cannulation or opacification. Difficult cannulation increases the risk of ERCP-related complications, especially postERCP pancreatitis (PEP), due to repeated and prolonged interventions $(6,7)$.

In cases of difficult biliary cannulation, the endoscopist should switch from standard biliary cannulation techniques to more advanced cannulation techniques such as pancreatic guidewire-assisted or precut techniques, or stop the procedure (8). Lack of operators' experience, anatomical variations of papillae (such as size, morphology, and location), presence of periampullary diverticulum (PAD), malignant infiltration, and anatomical alterations due to surgery are known to be some reasons for difficult cannulation. Surgery-related reasons for difficult cannulation include operations such as Billroth-2 gastrectomy and Roux-en-Y, in which it is considered difficult to reach the ampulla (8).

Few studies have discussed the impact of cholecystectomy on common bile duct (CBD) anatomy and whether this might affect the difficulty of ERCP. It was found that, patients with cholecystectomy had ectasia of bile ducts due to the loss of the gallbladder's reservoir function after cholecystectomy (9). CBD diameter is normal up to $6 \mathrm{~mm}$ and increases with age. Also, CBD diameter up to $8 \mathrm{~mm}$ in patients over 50 years old and up to $10 \mathrm{~mm}$ in patients with cholecystectomy was considered normal (10). In a recent study, ERCP was found to be significantly more difficult in patients with a history of complicated cholecystectomy than in patients with non-complicated cholecystectomy (11).

It is not known whether cholecystectomy is an independent risk factor for difficult biliary cannulation. We aimed to investigate the association of cholecystectomy with difficult biliary cannulation in patients who underwent ERCP for choledocholithiasis.

\section{Materials and Methods}

\section{Patients and study design}

This study employed as a retrospective study design at Ankara City Hospital, Turkey, after ethical approval

Correspondence to: Rasim Eren Cankurtaran, MD, Ankara Yildirim Beyazit University Faculty of Medicine Department of Gastroenterology, 06800 Cankaya- Ankara, Turkey. Fax: +90-312-906-2980. Phone: +90-5065091364. E-maildrcankurtaran88@gmail.com

Submission date : 13/01/2021

Acceptance date : 24/06/2021 
was received from the Ethics Committee of Ankara Yildirim Beyazit University (approval date: 09.09.2020, approval number: 26379996/86). Patients with naive papillae and those who underwent ERCP for common bile duct stones and/or sludge were included in this study. Patients with surgically altered anatomy (billroth 2 gastrectomy or roux-en-Y anastomosis), patients who were under 18 years old, who had prior malignant disease and sphincterotomy, who were pregnant, or who did not consent to participate in this research were excluded from the study. Data including age, gender, history of cholecystectomy, clinical presentation (acute cholangitis, biliary pancreatitis or biliary colic), periprocedural laboratory and radiological findings and ERCP results obtained from the patients were noted from the electronic database. These data and findings were compared between no-CCY and post-CCY groups.

\section{Endoscopic procedure:}

ERCPs were performed with a lateral scope (TJF 190; Olympus Optical) by an experienced endoscopist who performs $>700$ therapeutic ERCPs per year. In order to eliminate operator-dependent causes of difficult cannulation, ERCP was performed on patients in both groups by the same operator. The patients were sedated using intravenous midazolam and propofol by an anesthesiologist. ERCP was performed when common bile ductal stones and/or sludge (CBDSs) were detected through imaging methods such as Abdominal Ultrasound (AUS), Magnetic resonance cholangiopancreatography (MRCP), Endoscopic Ultrasound (EUS), and Computed tomography (CT).

Standard biliary cannulation (SBC) was initially performed using a guidewire-assisted technique with a sphincterotome. However, various advanced maneuvers were used, such as a pancreatic stent, double guidewire, precut techniques when SBC techniques failed. Patients for whom biliary cannulation failed in the first session underwent ERCP again in the next session. Feasible alternative strategies such as percutaneous-endoscopic rendezvous (PE-RV) were applied to patients who failed biliary cannulation in the second session. All patients who underwent ERCP were hospitalized and monitored for procedure-related complications.

\section{Definitions and criteria:}

Cannulation was considered difficult if it took more than 5 minutes or more than 5 attempts to cannulate the papilla, or if the pancreatic duct cannulation or opacification occurred more than once. ERCP-related complications such as pancreatitis, bleeding, asymptomatic hyperamylasemia, perforation, cholangitis, and cardiopulmonary complications were defined and graded according to standardized criteria in a consensus panel (12). PADs were divided into two categories as Intradiverticular papilla (IDP) and Juxtapapillary diverticula (JPD) according to the Lobo classification (13). Biliary cannulation time was defined as the duration between the first visualization of the papilla and deep cannulation.

\section{Statistical analysis:}

Data analyses were conducted using Statistical Package for the Social Sciences (SPSS 22.0 for Windows) software. The variables were investigated using visual (histograms and probability plots) and analytical methods (Kolmogrov-Smirnov tests) to determine whether they were normally distributed. In reporting descriptive statistics, data were expressed as mean \pm standard deviation (SD) for continuous values, median (minimum-maximum) for non-continuous values and categorical variables, and as frequencies and percentages $(\%)$ for nominal variables. Independent samples $t$ tests were used to compare the continuous values between nocholecystectomy (no-CCY) and post-cholecystectomy (post-CCY) groups. When necessary, Pearson's chisquare tests, Fisher's exact tests, or Likelihood tests were used to compare proportions in different groups. Variables with $\mathrm{p}<0.1$ in logistic univariate analysis were entered into multivariate analysis to confirm independent risk factors for difficult cannulation. Hosmer-lemeshow goodness of fit statistics were used to assess the model fit. The time duration between CCY and ERCP in patients with and without difficult cannulation were compared with Log-rank test. A p-value of $<0.05$ was considered statistically significant.

\section{Results}

A total of 858 patients underwent ERCP between February 2019 and July 2020.420 patients were excluded from the study according to the exclusion criteria. The remaining 438 patients were included in the present study and 347 of these patients were in the no-CCY group and 91 patients were in post-CCY group (Figure 1).

Selective biliary cannulation was successfully achieved in $280(86.4 \%)$ patients in the no-CCY group and in $61(70.9 \%)$ patients in the post-CCY group in the first session. A significant difference was found between post-CYY and no-CCY groups regarding the patients who were easily cannulated in the first session $(\mathrm{p}=0.001)$. The remaining patients were in the difficult cannulation group. Cannulation failed in the first session in $23(6.6 \%)$ patients in the no-CCY patient group and in $5(5.5 \%)$ patients in the post-CCY group. No significant differences were found between the patients for whom the cannulation failed in the first session in terms of their history of cholecystectomy. $(\mathrm{p}=0.813)$. These patients underwent ERCP again in the second session. Among these patients, cannulation failed again in 8 patients in the no-CCY group. In these patients, biliary cannulation was provided using the percutaneous rendezvous technique (Figure 1). 


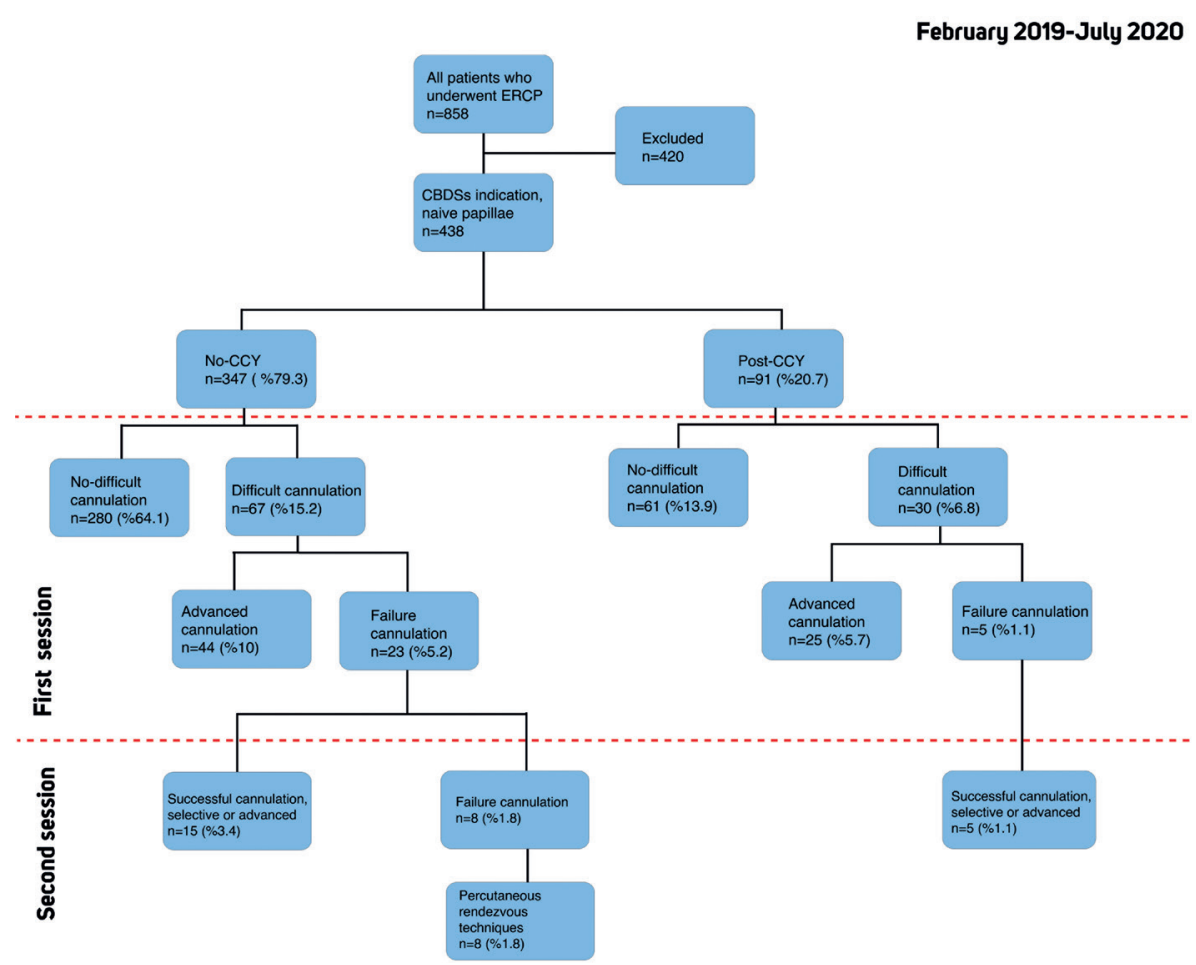

Figure 1. - Flowchart representing patient groups. CBDSs, Common bile duct Stones; CCY, cholecystectomy.

Table 1. - Comparison of no-CCY and post-CCY patient groups in terms of their demographics and clinical characteristics

\begin{tabular}{|c|c|c|c|c|}
\hline Patients & $\begin{array}{c}\text { No-CCY } \\
\text { Mean } \pm \text { SD } \\
\mathrm{N}(\%) \\
\mathrm{N}=347 \\
\end{array}$ & $\begin{array}{c}\text { Post-CCY } \\
\text { Mean } \pm \text { SD } \\
\mathrm{N}(\%) \\
\mathrm{N}=91 \\
\end{array}$ & $\begin{array}{c}\text { Total } \\
\text { Mean } \pm \mathrm{SD} \\
\mathrm{N}(\%) \\
\mathrm{N}=438 \\
\end{array}$ & p-value \\
\hline Mean Age (years) & $58.86 \pm 18.41$ & $61.43 \pm 14.71$ & $62.01 \pm 17.71$ & $0.17^{*}$ \\
\hline Female & $189(54.51)$ & $55(60.4)$ & $244(55.7)$ & $0.31^{* *}$ \\
\hline $\begin{array}{l}\text { Clinical presentation } \\
\text { Biliary Colic } \\
\text { Biliary Pancreatitis } \\
\text { Acute Cholangitis } \\
\end{array}$ & $\begin{array}{c}253(70.9) \\
75(21.6) \\
19(5.5)\end{array}$ & $\begin{array}{c}74(81.3) \\
11(12.1) \\
6(6.6)\end{array}$ & $\begin{array}{c}327(74.7) \\
86(19.6) \\
25(5.7)\end{array}$ & $0.11^{* * *}$ \\
\hline Total bilirubin (mg/dl) & $4.13 \pm 3.62$ & $3.61 \pm 3.16$ & $3.53 \pm 3.21$ & $0.19^{*}$ \\
\hline GGT (mg/dl) & $475.71 \pm 362.76$ & $483.73 \pm 431.53$ & $401.50 \pm 377.55$ & $0.86^{*}$ \\
\hline $\begin{array}{l}\text { Pre-ERCP imaging Modality used } \\
\text { AUS } \\
\text { MRCP } \\
\text { CT } \\
\text { EUS } \\
\end{array}$ & $\begin{array}{c}339(97.7) \\
127(36.6) \\
115(33.1) \\
10(2.9) \\
\end{array}$ & $\begin{array}{c}86(94.5) \\
45(49.5) \\
28(30.8) \\
10(11) \\
\end{array}$ & $\begin{array}{c}425(97.0) \\
172(39.2) \\
143(32.6) \\
20(4.5) \\
\end{array}$ & \\
\hline
\end{tabular}

*: independent samples $\mathrm{t}$ test, **: Pearson's chi squared test, ***: likelihood test, CCY: cholecystectomy, GGT: gamma glutamyl transferase, AUS:abdominal ultrasound, CT: computed tomography, MRCP: magnetic resonance cholangiopancreatography, EUS: endoscopic ultrasound.

Table 1 compares demographics and clinical characteristics of no-CCY and post-CCY groups. No significant differences were found between the no-CCY and post-CCY groups in terms of age, gender, clinical presentation, total bilirubin, and GGT $(\mathrm{p}=0.17, \mathrm{p}=0.31$, $\mathrm{p}=0.11, \mathrm{p}=0.19, \mathrm{p}=0.86$ respectively).

Table 2 compares the ERCP results and adverse events of the no-CCY and post-CCY groups. No statistically significant difference in the number of patients with successful cannulation in the first session, with overall successful cannulation and with the presence of PAD was found between the two groups $(\mathrm{p}=0.82, \mathrm{p}=0.21, \mathrm{p}=$
0.26 respectively). The median of total procedure time was significantly higher in post-CCY group than NoCCYgroup $(\mathrm{p}=0.007)$. The median cannulation times of patients with post-CCY group and no-CCY group were similar $(\mathrm{p}=0.122)$. A statistically significant difference was found in the number of patients with difficult cannulation in the post-CCY group compared to the noCCY group $(p=0.011)$, with more patients with difficult cannulation found in the post-CCY group. No significant differences were found in terms of difficult cannulation maneuvers between the no-CCY and post-CCY groups $(\mathrm{p}=0.52)$. No statistically significant differences were 
Table 2. - Comparison of ERCP results in no-CCY and post-CCY groups.

\begin{tabular}{|c|c|c|c|c|}
\hline Patients & $\begin{array}{c}\text { No-CCY } \\
\text { Mean } \pm \text { SD } \\
\mathrm{N}(\%)\end{array}$ & $\begin{array}{c}\text { Post-CCY } \\
\text { Mean } \pm \text { SD } \\
\mathrm{N}(\%) \\
\end{array}$ & $\begin{array}{c}\text { Total } \\
\mathrm{N}=438\end{array}$ & p-value \\
\hline Successful cannulation in the first session & $324(93.4)$ & $86(94.5)$ & 410 (93.6) & $0.82 *$ \\
\hline Overall success of cannulation & $339(97.7)$ & $91(100)$ & $438(100)$ & $0.21 *$ \\
\hline Total procedure time & $28.0(15.0-87.0)$ & $34.0(19.0-78.0)$ & $28.0(15.0-87.0)$ & $0.007 * * *$ \\
\hline Cannulation time & $3.0(1.0-68.0)$ & $3.0(1.0-34.0)$ & $3.0(1.0-68.0)$ & $0.122 * * *$ \\
\hline $\begin{array}{l}\text { Presence of PAD } \\
\text { IDP } \\
\text { JPD }\end{array}$ & $\begin{array}{l}34(9.8) \\
5(1.4) \\
29(8.4)\end{array}$ & $\begin{array}{c}13(14.3) \\
3(3.3) \\
10(11)\end{array}$ & $\begin{array}{c}47(10.8) \\
8(1.8) \\
39(8.9)\end{array}$ & $0.393^{* * * *}$ \\
\hline Difficult cannulation & $67(19.3)$ & $30(33.0)$ & $97(22.1)$ & $0.011 *$ \\
\hline $\begin{array}{l}\text { Frequencies of difficult cannulation maneuvers. } \\
\text { Pancreatic guidewire } \\
\text { Pancreatic stent } \\
\text { Precut fistulotomy } \\
\text { Precut papillotomy } \\
\text { Percutaneous rendezvous techniques } \\
\text { Selective biliary cannulation at subsequent procedure }\end{array}$ & $\begin{array}{l}27(40.3) \\
15(22.4) \\
3(4.5) \\
6(9.0) \\
8(11.9) \\
8(11.9)\end{array}$ & $\begin{array}{l}14(46.7) \\
8(26.7) \\
2(6.7) \\
3(10.0) \\
0(0) \\
3(10)\end{array}$ & $\begin{aligned} 41 & (42.3) \\
23 & (23.7) \\
5 & (5.2) \\
9 & (9.3) \\
8 & (8.2) \\
11 & (11.3)\end{aligned}$ & $0.52 * *$ \\
\hline $\begin{array}{l}\text { Adverse Events } \\
\text { Asymptomatic hyperamylasemia } \\
\text { Pancreatitis } \\
\text { Bleeding } \\
\text { Perforation } \\
\text { Cholangitis } \\
\text { Cardiopulmonary complication }\end{array}$ & $\begin{array}{l}40(11.5) \\
25(7.2) \\
7(2.2) \\
3(0.9) \\
1(0.3) \\
3(0.9)\end{array}$ & $\begin{array}{c}17(18.7) \\
7(7.7) \\
4(4.4) \\
1(1.1) \\
1(1.1) \\
0\end{array}$ & $\begin{array}{l}57(13.0) \\
32(7.3) \\
11(2.5) \\
4(0.9) \\
2(0.4) \\
3(0.6)\end{array}$ & $\begin{array}{l}0.09^{*} \\
0.83^{*} \\
0.26^{*} \\
1.00^{*} \\
0.38^{*} \\
1.00^{*}\end{array}$ \\
\hline
\end{tabular}

*Fisher's exact test, **Pearson's chi squared test, ***: Mann-Whitney U test, ****: Likelihood test, CCY: cholecystectomy, PAD: periampullary diverticulum, IDP: Intradiverticular papillae, JPD: Juxtapapillary diverticula.

Table 3. - Comparison of post-ERCP adverse events between groups with and without difficult cannulation

\begin{tabular}{|l|c|c|c|}
\hline Adverse Events: & $\begin{array}{c}\text { No-Difficult Cannulation } \\
\mathrm{N}(\%)\end{array}$ & $\begin{array}{c}\text { Difficult Cannulation } \\
\mathrm{N}(\%) \\
\mathrm{N}=341\end{array}$ & p-value \\
\hline Asymptomatic hyperamylasemia & $37(10.9)$ & $20(20.6)$ & $\mathbf{0 . 0 1 6}^{*}$ \\
\hline Pancreatitis & $20(5.9)$ & $12(12.4)$ & $\mathbf{0 . 0 4 4}$ \\
\hline Bleeding & $7(2.1)$ & $4(4.1)$ & $0.271^{*}$ \\
\hline Perforation & $4(1.2)$ & $1(1.0)$ & $0.907^{* *}$ \\
\hline Cholangitis & $2(0.6)$ & $0(0.0)$ & $0.450^{* *}$ \\
\hline Cardiopulmonary complication & $3(0.9)$ & $0(0)$ & $0.354^{* *}$ \\
\hline
\end{tabular}

*Fisher’s exact test, **Pearson’s chi squared test.

found between the no-CCY and post-CCY groups for post-ERCP adverse events including asymptomatic hyperamylasemia, PEP, bleeding, perforation, cholangitis, and cardiopulmonary complication $(\mathrm{p}=0.09$, $\mathrm{p}=0.83, \mathrm{p}=0.26, \mathrm{p}=1.00, \mathrm{p}=0.38, \mathrm{p}=1.00$, respectively). Perforation as one of the complications was severe in the patients in the post-CCY group and in 1 patient in the no-CCY group. While surgical treatment was applied to these patients, the size of perforation in the other patients in the no-CCY group was moderate and these patients were treated conservatively. In all patients with ERCP-related bleeding, the bleeding was mild and intraprocedural. In addition, PEP was mild in all patients who developed PEP.

Table 3 compares post-ERCP adverse events between the groups with and without difficult cannulation. Asymptomatic hyperamylasemia and PEP were signifi- cantly higher in the group with difficult cannulation compared to the group without difficult cannulation ( $\mathrm{p}=0.016$ and $\mathrm{p}=0.003$, respectively). No significant differences were found in the number of patients with bleeding, perforation, cholangitis, and cardiopulmonary complications $(\mathrm{p}=0.271, \mathrm{p}=0.907, \mathrm{p}=0.450, \mathrm{p}=0.354$, respectively).

Univariate analyses revealed that age $(\mathrm{p}=0.080)$ and history of cholecystectomy $(\mathrm{p}=0.006)$ were possible risk factors of difficult cannulation. When two possible risk factors were entered into multivariate analysis, only presence of history of cholecystectomy was found an independent risk factor of difficult cannulation (Odds ratio: 2.014; $95 \% \mathrm{Cl}$ 1.205-3.366; $\mathrm{p}=0.008$ ) (Table 4).

No significant differences were found in the time duration between CCY and ERCP in patients with and without difficult cannulation $(\mathrm{p}=0.56)$. 
Table 4. - Logistic regression analysis of factors associated with difficult cannulation

\begin{tabular}{|c|c|c|c|c|c|}
\hline Variables & $\begin{array}{l}\text { No-Difficult } \\
\text { Cannulation }\end{array}$ & Difficult Cannulation & $\begin{array}{c}\text { Univariate } \\
\text { P-value }\end{array}$ & $\begin{array}{c}\text { Multivariate } \\
\text { P-value }\end{array}$ & OR $(95 \% \mathrm{Cl})$ \\
\hline $\begin{array}{l}\text { Gender } \\
\text { Male } \\
\text { Female } \\
\end{array}$ & $\begin{array}{l}152(44.6) \\
189(55.9) \\
\end{array}$ & $\begin{array}{l}42(43.3) \\
55(56.7)\end{array}$ & 0.823 & & \\
\hline Age & 58.7117 .98 & 64.0116 .50 & 0.080 & 0.105 & $1.011(0.998-1.025)$ \\
\hline $\begin{array}{l}\text { History of Cholecystectomy } \\
\text { No } \\
\text { Yes }\end{array}$ & $\begin{array}{c}280(80.1) \\
61(17.9) \\
\end{array}$ & $\begin{array}{l}67(69.1) \\
30(30.9) \\
\end{array}$ & 0.006 & 0.008 & $2.014(1.205-3.366)$ \\
\hline $\begin{array}{l}\text { Clinical presentation } \\
\text { Biliary colic } \\
\text { Biliary pancreatitis } \\
\text { Acute cholangitis }\end{array}$ & $\begin{array}{c}249(73.0) \\
74(21.7) \\
18(5.3)\end{array}$ & $\begin{array}{l}78(80.4) \\
12(12.4) \\
7(7.2)\end{array}$ & 0.408 & & \\
\hline $\begin{array}{l}\text { Periampullary diverticulum } \\
\text { No } \\
\text { IDP } \\
\text { JPD }\end{array}$ & $\begin{array}{l}309(90.6) \\
5(1.5) \\
27(7.9)\end{array}$ & $\begin{aligned} 82 & (84.5) \\
3 & (3.1) \\
12 & (12.4)\end{aligned}$ & 0.222 & & \\
\hline
\end{tabular}

PAD: periampullary diverticulum, IDP: Intradiverticular papillae, JPD: Juxtapapillary diverticula.

\section{Discussion}

Demographic data and clinical findings were similar in patients with and without cholecystectomy. In the present study, $20.7 \%$ of patients who underwent ERCP for choledocholithiasis had a history of cholecystectomy. In a study which examined patients who underwent ERCP for choledocholithiasis, patients with cholecystectomy comprised $28 \%$ of the total patients. The same study reported that acute cholangitis was significantly more common in patients with cholecystectomy at the time of admission to the hospital (14). However, this study revealed no significant differences between the two groups in terms of the patients' clinical presentation.

One of the most important factors affecting SBC success is the experience of the operator. Several studies have shown that the SBC success rate increases after 350-400 ERCP are performed (15-17). In our study, the procedures were conducted by an experienced operator who performs more than 700 ERCPs annually. In a nation-wide study evaluating ERCP data conducted in multiple centers, more than 700 ERCPs were conducted in only 2 centers out of 43 (18). This supports that our center performs ERCP at high volume. Previous studies have reported that the successful biliary cannulation rates of experienced operators are expected to be between 95$100 \%$ (19). In our study, successful biliary cannulation rate in the first session of ERCP was found to be $93.6 \%$. No statistically significant differences were found in biliary cannulation success rates between patients with and without cholecystectomy in the first session.

Previous studies have reported difficult biliary cannulation frequency in the range of $5-35 \%$. These rates are known to be lower in experienced centers $(1-3,20,21)$. In our study, the frequency of difficult biliary cannulation among all patients was found to be $22.1 \%$. Pancreatic guidewire was the most commonly used maneuver $(42.3 \%)$. In addition, pancreatic stent $(23.7 \%)$, precut papillotomy $(9.3 \%)$ and precut fistulotomy $(5.2 \%)$ were used during the procedure. In another study conducted on difficult cannulation, $42.1 \%$ of the maneuvers used were pancreatic guidewire and $26.8 \%$ were pancreatic stents. The frequency rates of using these maneuvers are similar to the data obtained in our study (22). The frequency of maneuvers used in difficult biliary cannulation cases was similar in both patient groups. It is recommended that patients with unsuccessful biliary cannulation in the first session should undergo ERCP again a few days later in the second session. If cannulation is still not achieved, feasible alternative strategies such as surgery, percutaneous transhepatic biliary drainage (PTBD), endoscopic ultrasound guided biliary drainage (EUS$\mathrm{BD})$, percutaneous-endoscopic rendezvous (PE-RV), and laparoendoscopic rendezvous (LERV) should be applied (23). In our study, 28 patients with unsuccessful biliary cannulation in the first session underwent ERCP again a few days later in the second session. Because biliary cannulation was unsuccessful again in 8 of the patients who underwent ERCP a second time, PE-RV method was applied to these patients.

Difficult biliary cannulation makes the ERCP procedure more complicated due to the prolonged nature of the procedure and its repetitive manipulations. Difficult biliary cannulation increases the risk of ERCPrelated complications, especially the frequency of PEP. The frequency of PEP was significantly higher in patients with difficult biliary cannulation than in patients without difficult biliary cannulation, which is consistent with previous studies in the literature $(7,24,25)$. There were no statistically significant differences between patients with and without a history of cholecystectomy in terms of the frequency of PEP and other ERCP-related complications. Recent studies have reported the frequency of PEP to vary between $5-10 \%(26,27)$. The frequency of PEP in our study was $7.3 \%$ among all patients, which overlaps with the rates reported in the literature. In addition, asymptomatic hyperamylasemia was significantly more common in patients with difficult biliary cannulation. No 
statistically significant differences were found between the patient groups with and without difficult biliary cannulation in terms of the development of other ERCPrelated complications such as bleeding, perforation, cholangitis, and cardiopulmonary complications.

In a study evaluating the relationship between age and difficult cannulation, no significant differences were found between patients aged over and under 80 years in terms of difficult cannulation (22). However, this study did not find age to be an independent risk factor for difficult cannulation.

Difficult biliary cannulation is also caused by PAD. The frequency of PAD varies from $6-31.7 \%$ according to different diagnostic imaging methods (28-29). In our study, the presence of PAD constituted $10.8 \%$ of the entire patient group and was found with similar frequencies in both groups. In a study evaluating the relationship between PAD and difficult biliary cannulation, difficult cannulation was found in $25.5 \%$ of patients with PAD and in $16 \%$ of patients without PAD, and PAD was found to increase forced cannulation significantly (30). In another study, biliary cannulation was found to be significantly more difficult for IDPs, one of the diverticulum types, than for JPDs, in our study, PAD and its subtypes were not found to be independent risk factors for difficult biliary cannulation (31).

The clinic to which the patients applied can be considered another parameter that may cause difficult cannulation. According to the findings of a recent study, biliary cannulation was significantly more difficult in patients with biliary pancreatitis than patients with acute cholangitis, who underwent ECRP (32). In our study, no significant relationship was found between biliary pancreatitis, acute cholangitis or biliary colic and difficult cannulation.

There are limited studies evaluating whether the history of cholecystectomy is a risk factor for difficult cannulation. In a recently published study, biliary cannulation was found to be more difficult and the total procedure time was significantly longer in patients with a history of complicated cholecystectomy (11). In our study, we found difficult biliary cannulation to be significantly more frequent in the post-CCY patient group. Similarly, we found the total procedure time to be significantly longer in patients with cholecystectomy. The cannulation time was unexpectedly similar in both groups, suggesting that the difficult cannulation in patients with cholecystectomy may be due to other criteria.

There was no change in the localization of the ampulla in patients who underwent cholecystectomy. As such, cholecystectomy does not appear to be among the operations such as Billroth-2 gastrectomy and Rouxen $\mathrm{Y}$ anastomosis that cause surgery-related secondary anatomical changes. Previous studies have reported changes in the sphincter of Oddi pressure and motility in patients after cholecystectomy. These changes may be due to the removal of the inhibitory effect of the cholecystokinin hormone on the sphincter of Oddi after cholecystectomy $(33,34)$. Another study found that some patients had increased sphincter of Oddi basal pressure after cholecystectomy (35). Although cholecystectomy does not change the anatomy of the papilla, we think that motility and pressure changes in the sphincter of Oddi, which is the smooth muscle surrounding the papilla, may cause difficult biliary cannulation. However, because our study was a retrospective study, no manometric evaluations were made in terms of sphincter of Oddi dysfunction.

In our study, we evaluated whether the time between surgery and ERCP was associated with difficult biliary cannulation in patients with cholecystectomy. Although the median duration between cholecystectomy and ERCP in the patients with difficult biliary cannulation was longer than the patients without difficult biliary cannulation, this was not statistically significant.

This study had some limitations. First, the most important limitation of this study is its retrospective design and data were collected from patients in a single center. Second, the type operation that patients with cholecystectomy underwent could not be accessed from the database. The effect of previous open or laparoscopic surgery in patients with cholecystectomy on difficult biliary cannulation could not be evaluated. Finally, manometric evaluations of the sphincter of Oddi were not made.

This is the first study to investigate difficult biliary cannulation in patients with cholecystectomy. The results showed that patients who underwent ERCP for common bile duct stones after cholecystectomy had significantly more difficulties in biliary cannulation. Although these data originate from procedures performed by an experienced endoscopist in high volume setting, it is unclear whether these results can be extrapolated to other centers or endoscopists. It is unknown whether cholecystectomy is an independent risk factor for difficult biliary cannulation, and this should be investigated through large-scale prospective studies conducted in multiple centers.

\section{Acknowledgements}

We thank to Damla Cankurtaran for statistical analyses.

\section{Conflict of interest statement}

Authors declareted that they have no conflict of interest.

\section{References:}

1. NALANKILLII K, KANNUTHURAİ S, MOSS A. A modern approach to ERCP: maintaining efficacy while optimising safety. Dig Endosc, 2016, 28: 70-76.

2. HUANG L, YU QS., ZHANG Q., LIU JD., WANG Z. Comparison between double-guidewire technique and transpancreatic sphincterotomy technique for difficult biliary cannulation. Dig Endosc, 2015, 27: 381-387. 
3. ZHANG QS., HAN B., XU JH., GAO P., SHEN YC. Needle-knife papillotomy and fistulotomy improved the treatment outcome of patients with difficult biliary cannulation. Surg Endosc, 2016, 30: 5506-5512.

4. DUMONCEAU JM., ANDRIULLİ A., ELMUNZER BJ., MARIAANI A., MEISTER T., DEVIERE J., et al. European Society of Gastrointestinal Endoscopy. Prophylaxis of post-ERCP pancreatitis: European Society of Gastrointestinal Endoscopy (ESGE) Guideline - updated June 2014. Endoscopy, 2014, 46: 799-815.

5. TESTONI PA., MARIANI A., AABAKKEN L., ARVANITAKIS M., BORIES E., COSTAMAGNA G., et al. Papillary cannulation and sphincterotomy techniques at ERCP: European Society of Gastrointestinal Endoscopy (ESGE) Clinical Guideline. Endoscopy, 2016, 48: 657-683.

6. HALTTUNEN J., MEISNER S., AABAKKEN L., ARNELO U., GRÖNROOS J., HAUGE T., et al. Difficult cannulation as defined by a prospective study of the Scandinavian Association for Digestive Endoscopy (SADE) in 907 ERCPs. Scand J Gastroenterol 2014, 49: 752-758.

7. FREEMAN ML., DISARIO JA., NELSON DB., FENNERTY MB., LEE JG., BJORKMAN DJ., et al. Risk factors for post-ERCP pancreatitis: a prospective, multicenter study. Gastrointest Endosc 2001, 54: 425-434.

8. BERRY R., HAN JY., TABIBIIAN JH. Difficult biliary cannulation: Historical perspective, practical updates, and guide for the endoscopist. World journal of gastrointestinal endoscopy, 2019, 11: 5.

9. PARK SM., KIM WS., BAE IH., KIM JH., RYU DH., JANG LC., et al. Common bile duct dilatation after cholecystectomy: a one-year prospective study. Journal of the Korean Surgical Society, 2012, 83: 97.

10. SENTÜRK S., MIROGLU TC., BILLICİ A., GUMUS H., TEKIN RC., EKİCI F., et al. Diameters of the common bile duct in adults and postcholecystectomy patients: a study with 64-slice CT. European journal of radiology, 2012, 81 $39-42$.

11. SELEEM WM., HANAFY AS., ABD-ELSALAM S., BADAWI R. Impact of laparoscopic cholecystectomy on the complexity of endoscopic retrograde cholangiopancreatography. European journal of gastroenterology \& hepatology, 2021.

12. COTTON PB., LEHMAN G., VENNES J., GEENEN JE., RUSSELL RC., MEYERS WC., et al. Endoscopic sphincterotomy complications and their management: an attempt at consensus. Gastrointest Endosc, 1991, 37: $383-$ 393.

13. LOBO DN., BALFOUR TW., IFTIKHAR SY. Periampullary diverticula: consequences of failed ERCP. Annals of the Royal College of Surgeons of England, 1998, 80: 326.

14. SPATARO J., TOLYAMAT M., KISTLER CA., JACOBS M., FITCH J., Ahmed M. Prevalence and Risk Factors for Choledocholithiasis After Cholecystectomy. American Journal of Gastroenterology, 2017, 112: 32-33

15. SHAHIDİ N., OU G., TELFORD J., ENNS R. When trainees reach competency in performing ERCP: a systematic review. Gastrointest Endosc, 2015, 81: 1337-1342

16. VOİOSU T., BENGUS A., VOIOSU A., RIMMBAS M., ZLATE A., HAIDAR A., et al. Trainee caseload correlates with ERCP success rates but not with procedure-related complications: results from a prospective study (the QUASIE cohort). Endosc Int Open, 2016, 4: E409-414.

17. VERMA D., GOSTOUT CJ., PETERSEN BT., LEVY MJ., BARON TH., Adler DG. Establishing a true assessment of endoscopic competence in ERCP during training and beyond: a single-operator learning curve for deep biliary cannulation in patients with native papillary anatomy. Gastrointestinal endoscopy, 2007, 65: 394-400.

18. SNAUWAERT, C., DEKONINCK, X., MOREELS, T. Current ERCP practice in Belgium: the BSGIE survey. Acta Gastro-enterologica Belgica, 2021, 84 (1): 73-77.

19. COLTON JB., CURRAN CC. Quality indicators, including complications, of ERCP in a community setting: a prospective study. Gastrointest Endosc, 2009, 70: 457-467.
20. BAİLEY AA., BOURKE MJ., WILLIAMS SJ., WALSH PR., MURRAY MA., LEE EY., et al. A prospective randomized trial of cannulation technique in ERCP: effects on technical success and post-ERCP pancreatitis. Endoscopy, 2008, 40: 296-301.

21. CENNAMO V., FUCCIO L., ZAGARİ RM. Can early precut implementation reduce ERCP related complication risk? Meta-analysis of randomized controlled trials. Endoscopy, 2010, 42: 381-388.

22. TABAK F., WANG HS., Lİ QP., GE XX., WANG F., JI GZ., et al. Endoscopic retrograde cholangiopancreatography in elderly patients: Difficult cannulation and adverse events. World J Clin Cases, 2020, 26, 8: 2988-2999.

23. CHEN Q., JiN P., JI X., DU H., LU J. Management of difficult or failed biliary access in initial ERCP: A review of current literature. Clin Res Hepatol Gastroenterol, 2019, 43: 365-372

24. WILLIAMS EJ., TAYLOR S., FAIRCLOUGH P, HAMLYN A., LOGAN RF., MARTIN D., et al. Risk factors for complication following ERCP; results of a large-scale, prospective multicenter study. Endoscopy, 2007, 39: 793-801

25. BAILLEY AA, BOURKE MJ, KAFFES AJ, BYTH K., LEE EY, WILLIAMS SJ. Needle-knife sphincterotomy: factors predicting its use and the relationship with post-ERCP pancreatitis (with video). Gastrointest Endosc, 2010, 71: 266-271

26. FREEMAN ML., NELSON DB., SHERMAN S., HABER GB., HERMAN ME., DORSHER PJ., et al. Complications of endoscopic biliary sphincterotomy. New England Journal of Medicine ,1996, 335: 909-919.

27. KOCHAR B., AKSHINTALA VS., AFGHANI E., ELMUNZER BJ., KIM KJ., LENNON AM., et al. Incidence, severity, and mortality of post-ERCP pancreatitis: a systematic review by using randomized, controlled trials. Gastrointest Endosc, 2015, 81: 143-149.

28. CAPPELL MS., MOGROVEJO E., MANICKAM P., BATKE M. Endoclips to facilitate cannulation and sphincterotomy during ERCP in a patient with an ampulla within a large duodenal diverticulum: case report and literature review. Dig Dis Sci, 2015, 60: 168-173.

29. BOIX J., LORENZO-ZUNIGA V., ANANOS F., DOMENECH E., MORILLAS RM., GASSULL MA. Impact of periampullary duodenal diverticula at endoscopic retrograde cholangiopancreatography: a proposed classification of periampullary duodenal diverticula. Surgical Laparoscopy Endoscopy \& Percutaneous Techniques, 2006, 16: 208-211.

30. SFARTI VC., BALAN JR G., CHIRIAC AȘ., STANCIU C., BALAN G., GAFENCU-ŞAVLOVSCHI DUMITRIŢA., et al. Endoscopic retrograde cholangiopancreatography (ERCP) in patients with periampullary diverticula. Rom J Morphol Embryol, 2018, 59: 833-837.

31. YUE P., ZHU KX., WANG HP., MENG WB., LIU JK., ZHANG L., et al. Clinical significance of different periampullary diverticulum classifications for endoscopic retrograde cholangiopancreatography cannulation. World Journal of Gastroenterology, 2020, 26: 2403.

32. PECSİ D., GODİ S., HEGYİ P., HANAK L., SZENTESİ A., ALTORJAY I., et al. Hungarian Endoscopy Study Group. ERCP is more challenging in cases of acute biliary pancreatitis than in acute cholangitis-Analysis of the Hungarian ERCP registry data. Pancreatology, 2021, 21: 59-63.

33. BLAUT U., MARECIK J., THOR PJ. Zaburzenia motoryki zwieracza Oddiego--czynnik etiologiczny czy skutek przewodowej kamicy zółciowej [Sphincter of Oddi motility disturbances--etiologic factor or the consequence of choledocholithiasis]. Folia Med Cracov, 1999, 40: 93-105

34. LUMAN W., WILLIAAMS AJ., PRYDE A., SMITH GD., NIXON SJ., HEADING RC., et al. Influence of cholecystectomy on sphincter of Oddi motility. Gut , 1997, 41: 371-374.

35. GEENEN JE., HOGAN WJ., DODDS WJ., TOOULI J., VENU RP. The efficacy of endoscopic sphincterotomy after cholecystectomy in patients with sphincter-of-Oddi dysfunction. $N$ Engl J Med, 1989, 12,320: 82-87. 